Research Article

\title{
Climate Comfort Evaluation of National 5A Tourist Attractions in the Mainland of China Based on Universal Thermal Climate Index
}

\author{
Lei Hua $\mathbb{D}^{1},{ }^{1}$ Hailin Zhang $\mathbb{D}^{1,},{ }^{1,2}$ Xiuyun Liu, ${ }^{1}$ Xiufeng Yang, ${ }^{1}$ He Duan, ${ }^{1}$ and Tieniu Wu ${ }^{1,2}$ \\ ${ }^{1}$ College of Urban and Environmental Sciences, Central China Normal University, Wuhan 430079, China \\ ${ }^{2}$ Key Laboratory for Geographical Process Analysis \& Simulation, Wuhan, Hubei Province, China \\ Correspondence should be addressed to Hailin Zhang; hailzhang@mail.ccnu.edu.cn
}

Received 11 February 2020; Revised 20 August 2020; Accepted 16 September 2020; Published 28 September 2020

Academic Editor: Panagiotis Nastos

Copyright (C) 2020 Lei Hua et al. This is an open access article distributed under the Creative Commons Attribution License, which permits unrestricted use, distribution, and reproduction in any medium, provided the original work is properly cited.

Based on the daily climate data from 839 meteorological stations covering the 2014-2017 period in the mainland of China, the Universal Thermal Climate Indices (UTCI) were calculated and the UTCI of 247 national 5A tourist attractions in the mainland of China are obtained with ordinary kriging interpolation method. Then, a spatial analysis of all the attractions was carried out based on UTCI. The results showed that the mainland of China's annual average UTCI is generally distributed as strip-belts along a latitudinal direction and the climate comfort level gradually decreases from south to north. Significant regional differences in climate comfort results are obtained between the southeast coastal areas and the northwest inland. It was found that the number of attractions with the best climate comfort level is relatively high in spring and autumn while it is less in summer and winter. Considering the climate comfort levels, the attractions are grouped into five categories of "comfortable during spring and autumn," "comfortable during winter," "comfortable during spring, autumn, and winter," "comfortable during spring, summer, and autumn," and "uncomfortable during the four seasons" to carry out the study for determining the most convenient period of the year in terms of climate comfort.

\section{Introduction}

Climate comfort, also known as thermal comfort, usually refers to the meteorological conditions that humans can ensure their normal physiological metabolism to feel comfortable while not needing any adjustment for heat prevention and/or cold protection [1]. The climate comfort research is based on the heat exchange between the human physiological sense and the atmosphere [2]. From the perspective of meteorology, it analyzes the comfort index of human physiological touch under different climatic conditions $[3,4]$. Climate comfort is a key factor affecting the population's mobility in the natural environment so that it is also an important factor affecting tourism development. The climate comfort conditions are an important determinant of tourists' choice for destinations [5-8].
Research on climate comfort has been around for nearly a hundred years. As early as the 1920s, some scholars began to pay attention to climate comfort research and not only proposed but also established a variety of assessment concepts and models. Early research was based on statistical empirical indicators. Houhton FC proposed an equal comfort line including the variables of temperature and humidity, which also pioneered the use of empirical models for the comfort evaluation [9]. Early empirical indicators mainly included Effective Temperature (ET) [10], Wet Bulb Globe Temper (WBGT) [11], Temperature-Humidity Index (THI) [12], and Wind Chill Index (WCI) [13, 14]. The empirical indices are easy to calculate and be understood by the public. However, they contain unreasonable calculations to reduce the accuracy of the results so that they cannot meet the basic requirements of the good correspondence between the assessment values and the human thermophysiological 
state. The empirical indices are also limited in terms of time and space scales [15]. For this reason, a reasonable human comfort model is required to be based on the human body heat exchanger system by taking the influence of various issues, such as environmental factors, human metabolic heat dissipation, and clothing thermal resistance into account [16]. With the development of biometeorology and computer technology after the 1960s, a variety of indices including Predicted Mean Vote (PMV) [17], Predicted Percentage of Dissatisfied (PPD) [14], Standard Effective Temperature (SET) [18], and Physiological Equivalent Temperature (PET) [19] were proposed for the study of climate comfort. However, the abovementioned indices are replaced gradually due to the lack of precise calculation of the heat exchange between the human body and the environment. With the development of multidisciplinary integration, climate comfort research became increasingly rigorous and convenient. Under the umbrella of the WMO Commission on Climatology, 45 scientists from 23 countries in the fields of thermal physiology, mathematical modeling, occupational medicine, meteorological data handling, and application development are organized to work together. With the help of multidisciplinary research and taking the responding factors, such as heat conduction, long- and short-wave radiation, and skin moisture evaporation, into consideration, a Universal Thermal Climate Index is proposed based on multinode model (Universal Thermal Climate Index, UTCI) [15]. Compared with the existing models, the operational procedure of UTCI shows plausible responses to humidity and radiative loads from the environment with higher temperatures as well as the wind in colder conditions [15]. Moreover, UTCI is the most comprehensive and universal indicator of human thermal and cold stress at present. Compared with other indicators, UTCI has the advantage of applying a variety of climate types, being sensitive to changes in climate factors, and better describing the process of change in the thermal environment.

Over the past 20 years, the tourism industry has developed rapidly in China, especially in the mainland of China. Many new tourism resources and tourism destinations are being established due to the great potential for tourism development by keeping in mind that many tourism activities are climatesensitive or climate-dependent [20]. Moreover, China's climate has a high seasonal variability especially heat stress during summer and cold stress during winter [21]. On the other hand, most regions have favorable climate conditions for relatively a short period and it makes a significant impact on tourism [22]. In addition, China covers a wide area with a complex topography and diverse climate zones that lead to substantial regional disparities in climate [21]. These factors highlight the necessity of an assessment nationwide considering the climate condition in terms of tourism. Numerous studies are conducted to evaluate climate comfort conditions and their implications for tourism in China [20, 22-31]. However, most of these studies were carried out on a local scale, such as a province, city, or resort. Ge et al. [22] provided a nationwide assessment of thermal conditions in China at both annual and seasonal scales by using UTCI. It was also an important attempt to implement an application on climate comfort assessment on a larger scale [22]. The mainland of China is experiencing a transformation from traditional sightseeing to resort tourism so that national 5A tourist attractions are the most popular destinations from this perspective. This study emphasizes a special evaluation of the comfort conditions for attractions in the mainland of China based on UTCI by using an ordinary kriging interpolation method. The results of this study are expected to be helpful for the optimization of the tourism industry and the development of high-quality tourism destinations.

\section{Data and Methods}

2.1. Data. The meteorological data from 839 meteorological stations in the mainland of China is provided by China Meteorological Science Data Sharing Network (Figure 1). The data covers the 2014-2017 period and includes daily average temperature, water vapor pressure, and wind speed parameters. The dataset of national $5 \mathrm{~A}$ tourist attractions (hereafter referred to as "attractions") is obtained from the China Tourism Yearbook published by the China National Tourism Administration in 2017.

\subsection{Methods}

\subsubsection{Universal Thermal Climate Index and Climate Comfort} Grading. This study uses a simplified UTCI calculation method, which refers to the temperature that enables the human body to produce the same physiological response as the actual environment in the standard reference conditions. The standard reference conditions for the model include $0.5 \mathrm{~m} / \mathrm{s}$ wind speed at $10 \mathrm{~m}, 50 \%$ relative humidity, temperature less than $29^{\circ} \mathrm{C}$ at $2 \mathrm{~m}$, and $20 \mathrm{hPa}$ vapor pressure for temperature higher than $29^{\circ} \mathrm{C}$ at $2 \mathrm{~m}$ as well as the walking speed of $4 \mathrm{~km} / \mathrm{h}$ for an adult which is equivalent to a metabolic rate of $135 \mathrm{~W} / \mathrm{m}^{2}$. The climate comfort level is categorized according to UTCI as provided in Table 1 . The calculation formula is defined by Accent et al. [29] as

$$
\mathrm{UTCI}=f\left(T_{a}, T_{m r t}, V_{a}, \mathrm{RH}\right),
$$

where $T_{a}$ is the temperature $\left({ }^{\circ} \mathrm{C}\right), T_{m r t}$ is the radiation temperature $\left({ }^{\circ} \mathrm{C}\right), V_{a}$ is the wind speed $(\mathrm{m} / \mathrm{s})$, and $\mathrm{RH}$ is the relative humidity (\%).

The calculation of UTCI is implemented by the software BioKlima 2.6. The average radiant instead of temperature, which is required by the calculation of UTCI, is not directly observed so that cloud data, air pressure, and solar elevation angle are used as surrogate variables. Except for the solar elevation angle, other factors are derived by using site observation data. The solar elevation angle, for instance, is obtained by 


$$
\begin{aligned}
\sin H & =\sin \varphi \times \sin \delta+\cos \varphi \times \cos \delta \times \cos t,\left(-90^{\circ} \leq H \leq 90^{\circ}\right), \\
t & =15(n-12), \\
\delta & =23.45^{\circ} \times \sin \left[(N-80.25) \times\left(\frac{1-N}{9500}\right)\right], \\
\cos t & =-\operatorname{tg} \varphi \times \operatorname{tg} \delta,
\end{aligned}
$$

where $H$ is the solar elevation angle; $t$ is the solar hour angle; $\delta$ is the declination angle; $n$ is the obtained observation data; $N$ is the number of observations for days; and $\varphi$ is the latitude; the negative value is the sunrise angle, while the positive value is the sunset angle.

2.2.2. Kriging Interpolation Method. Ordinary kriging is an estimation technique known as the best linear unbiased estimator which uses the semivariogram method. Its interpolation through variography provides an interpolation estimate using the observed values and their spatial relationships. Ordinary kriging interpolation, which is detailed in the literature [33], is used in this study.

The UTCI for all 839 meteorological stations is calculated as the first step. Then, spatial interpolation is performed for each cell with $10 \mathrm{~km} * 10 \mathrm{~km}$ grid points over the study area by the ordinary kriging method using ArcGIS software. According to the criteria listed in Table 1, climate comfort level is assigned for each attraction based on the UTCI value. Finally, the spatial distribution of climate comfort level for 247 national 5A tourist attractions is analyzed.

\section{Results}

3.1. Annual Variability. As shown in Figure 2, the annual average climate comfort level in the mainland of China is generally distributed in a strip-like spatial pattern along a latitudinal direction. The climate comfort level also gradually decreases from southeast to northwest. Due to the influence of topographic factors, the Qinghai-Tibet Plateau and the Tarim Basin have an island-like spatial pattern. The central part of the Qinghai-Tibet Plateau represents a climate comfort level of 4 due to its high altitude on the plateau and mountains. The Tarim Basin has an island-like spatial pattern with a climate comfort level of 5 due to its higher surrounding.

The annual average climate comfort evaluation results showed that there are 195 attractions with a climate comfort level of 6 , which is the optimal level for a human, indicating that the climate is comfortable. This group accounts for $80 \%$ of all tourism locations (Table 2). These tourist attractions are mainly located in the southeast where Yanshan, Taihang, Qinling, Wushan, and Hengduan Mountains are found including Shandong, Henan, Hubei, Chongqing, Guizhou, Yunnan, Anhui, Jiangsu, and Zhejiang in the central and eastern regions of China. Forty-four attractions with the comfort level of 5 and slight cold stress mainly occurred in the areas of Tianshan, Kunlun, Qilian, Helan, Yanshan, and
Changbai Mountains as well as Inner Mongolia, Xinjiang, Gansu in the northeast of China by accounting for $17.8 \%$. Only two attractions, the Aershan-Chaihe attraction in the Inner Mongolia Autonomous Region and the Mohe Arctic Village attraction in the northeastern of China, are located in the strip-belt with the annual climate comfort level of 4 since they are strongly affected by the Daxinganling and the Xiaoxing'anling Mountains. The strip-belt area has moderate cold stress which causes to feel coolish. In addition, 6 attractions with a comfort level of 7 indicate that annual climate conditions have strong thermal stress during the year because of being located in the Hainan Island, on the northern edge of the tropics with high temperature, humidity, and average radiation all year round.

3.2. Seasonal Variability. Figure 3 shows the spatial distribution of the climate comfort level with respect to seasons. The climate comfort distribution is similar during spring and autumn. The attractions have significant regional differences in different seasons with strip-like spatial distribution characteristics. As shown in Table 2 and Figure 3, the overall number of attractions with good climate comfort is obtained relatively higher in spring and autumn while it is less in summer and winter.

The spatial distribution of the comfortable attractions during spring and autumn is similar. They are mainly concentrated in the areas along the rivers and oceans including Jiangsu, Anhui, Hunan, Hubei, Guizhou, Zhejiang, and Fujian. Due to the influence of monsoon climate and aerosol changes and the significant thermal inertia of oceans and rivers $[34,35]$, the temperature in the vicinity of these areas regulates these areas, making these areas cooler in summer, warmer in winter, and more comfortable in spring and autumn. Under the influence of subtropical high, the spatial distribution of the attractions in the summer season is the most noticeable one because the most comfortable areas are moved northward. The best climate comfort levels are located mostly in high-latitude and high-altitude regions, mainly in Xinjiang, Inner Mongolia, northern Qinghai, Gansu, northwestern Shanxi, Heilongjiang, Hebei, Liaoning, and Beijing.

The number of attractions with the best climate comfort level of 6 during autumn is the highest and it accounts for $83 \%$. In winter, the number of areas that experience "no thermal stress" in the same category is only 64 and located in the south of the middle and lower reaches of the Yangtze River because of the Siberian high-pressure influence. On the other hand, the number of attractions with the climate 


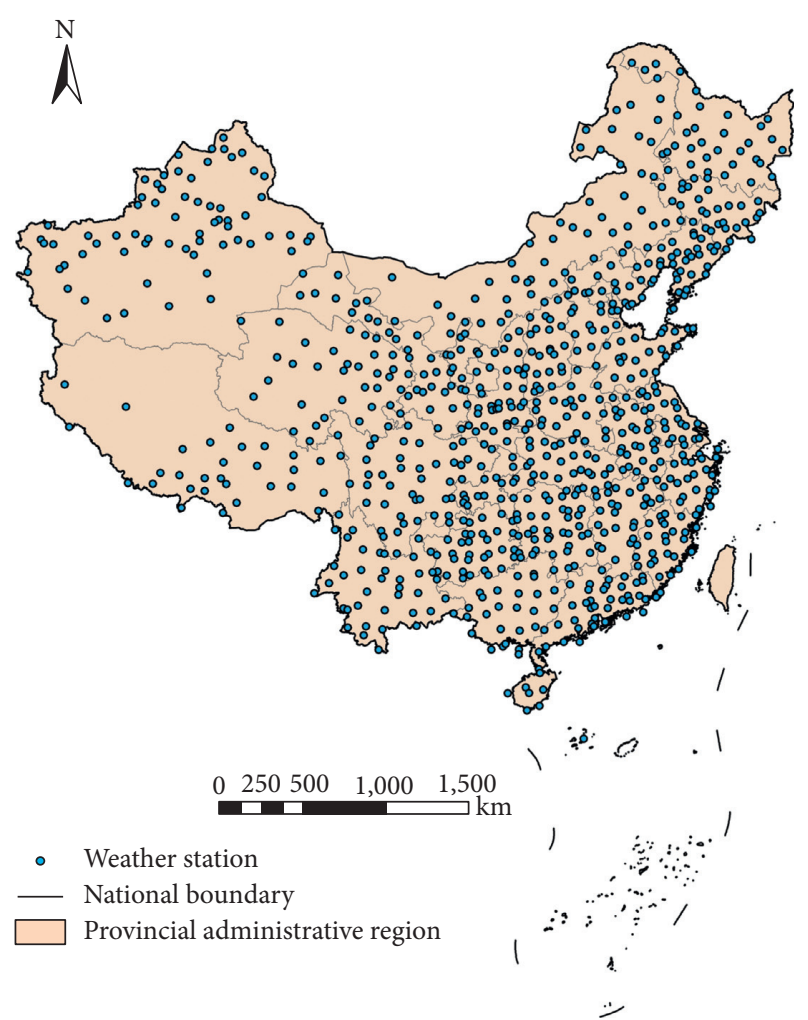

FIGURE 1: Distribution of meteorological stations in the mainland of China.

TABLE 1: UTCI equivalent temperatures in terms of thermal stress and climate comfort level [32].

\begin{tabular}{lcc}
\hline Climate comfort level & UTCI $\left({ }^{\circ} \mathrm{C}\right)$ & Stress category \\
\hline Freezing (1) & $<-40$ & Extreme cold stress \\
Chilly (2) & $-40 \sim-27$ & Very strong cold stress \\
Cold (3) & $-27 \sim-13$ & Strong cold stress \\
Coolish (4) & $-13 \sim 0$ & Moderate cold stress \\
Cool (5) & $0 \sim 9$ & Slight cold stress \\
Comfortable (6) & $9 \sim 26$ & No thermal stress \\
Warm (7) & $26 \sim 32$ & Moderate heat stress \\
Hot (8) & $32 \sim 38$ & Strong heat stress \\
Hottish (9) & $38 \sim 46$ & Very strong heat stress \\
Torrid (10) & $>46$ & Extreme heat stress \\
\hline
\end{tabular}

comfort level of 5 is the highest (namely, 108) where the climate conditions with moderate cold stress are not suitable for travel.

For an extended study, the seasonal comfort characteristic is classified into five categories of "comfortable during spring and autumn," "comfortable during winter," "comfortable during spring, autumn, and winter," "comfortable during spring, summer, and autumn," and "uncomfortable during the four seasons (Figure 4)."

The majority $(72 \%)$ of the attractions with the best climate comfort level of 6 are located in category I (comfortable during spring and autumn) according to Figure 4. These tourist attractions are located along the southeast of the line formed by Taihang, Qinling, and Wushan Mountains including north of Hainan Island with an elevation

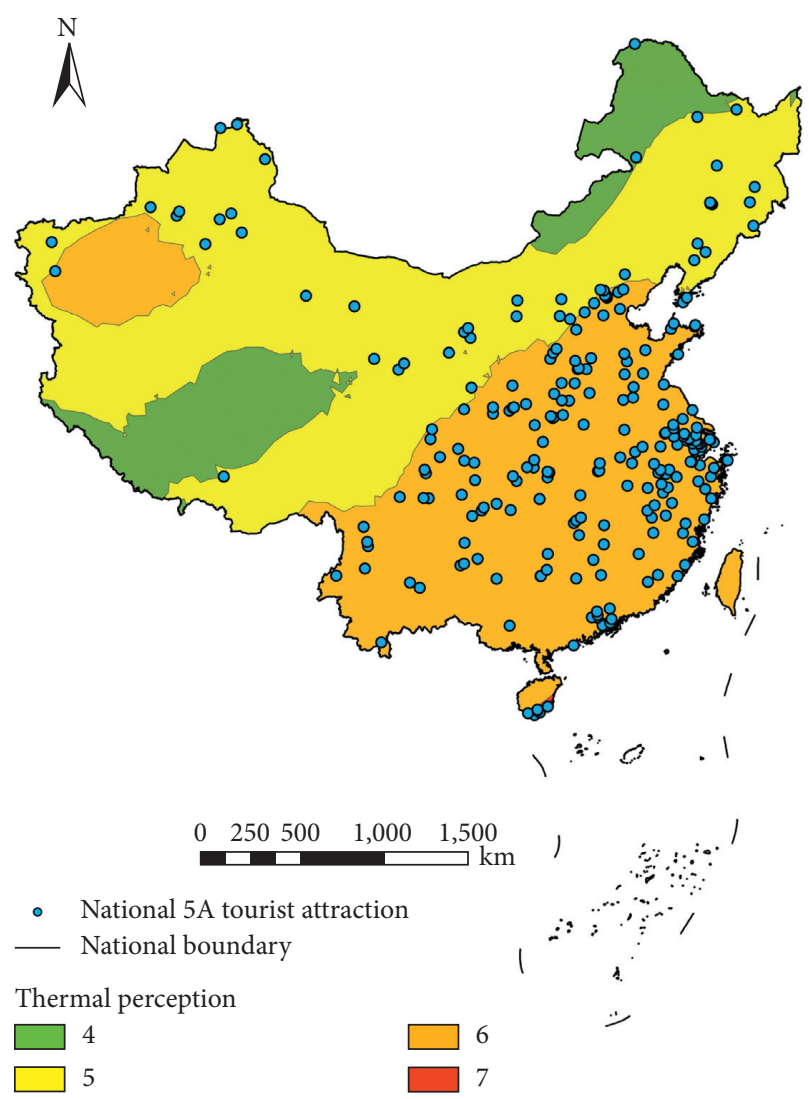

FIgURE 2: Spatial distribution of annual average climate comfort in the mainland of China.

TABLE 2: The number of national 5A tourist attractions with respect to climate comfort levels in the mainland of China (the total number of scenic spots is 247).

\begin{tabular}{lccccc}
\hline & Level 3 & Level 4 & Level 5 & Level 6 & Level 7 \\
\hline Annual & - & 2 & 44 & 195 & 6 \\
Spring & - & 6 & 48 & 185 & 7 \\
Summer & - & - & 2 & 113 & 132 \\
Autumn & - & 1 & 27 & 206 & 13 \\
Winter & 13 & 64 & 105 & 61 & 4 \\
\hline
\end{tabular}

Note: "-" indicates that there is no national $5 \mathrm{~A}$ tourist attraction for the corresponding level.

below 1000 meters. The numbers of comfortable attractions during "spring, autumn, and winter" (category II) and "comfortable during winter" (category V) are 51 and 64, respectively. They are mainly distributed in the lower-latitude areas of the south of the middle and lower reaches of the Yangtze River, including Yunnan, Guizhou, Hunan, Jiangxi, Zhejiang, Fujian, Guangdong, and Guangxi. There are 61 comfortable attractions during "spring, summer, and autumn" (category III), distributed in the central part of China, near the Taihang and Qinling Mountains including Beijing, Hebei, Shanxi, Shaanxi, southern Sichuan, Yunnan, and Guizhou. These tourist attractions are characterized by having relatively longer comfortable days for tourists. Only 7 attractions in the south of Hainan Island are obtained to be "uncomfortable during the four seasons" (category V) where 

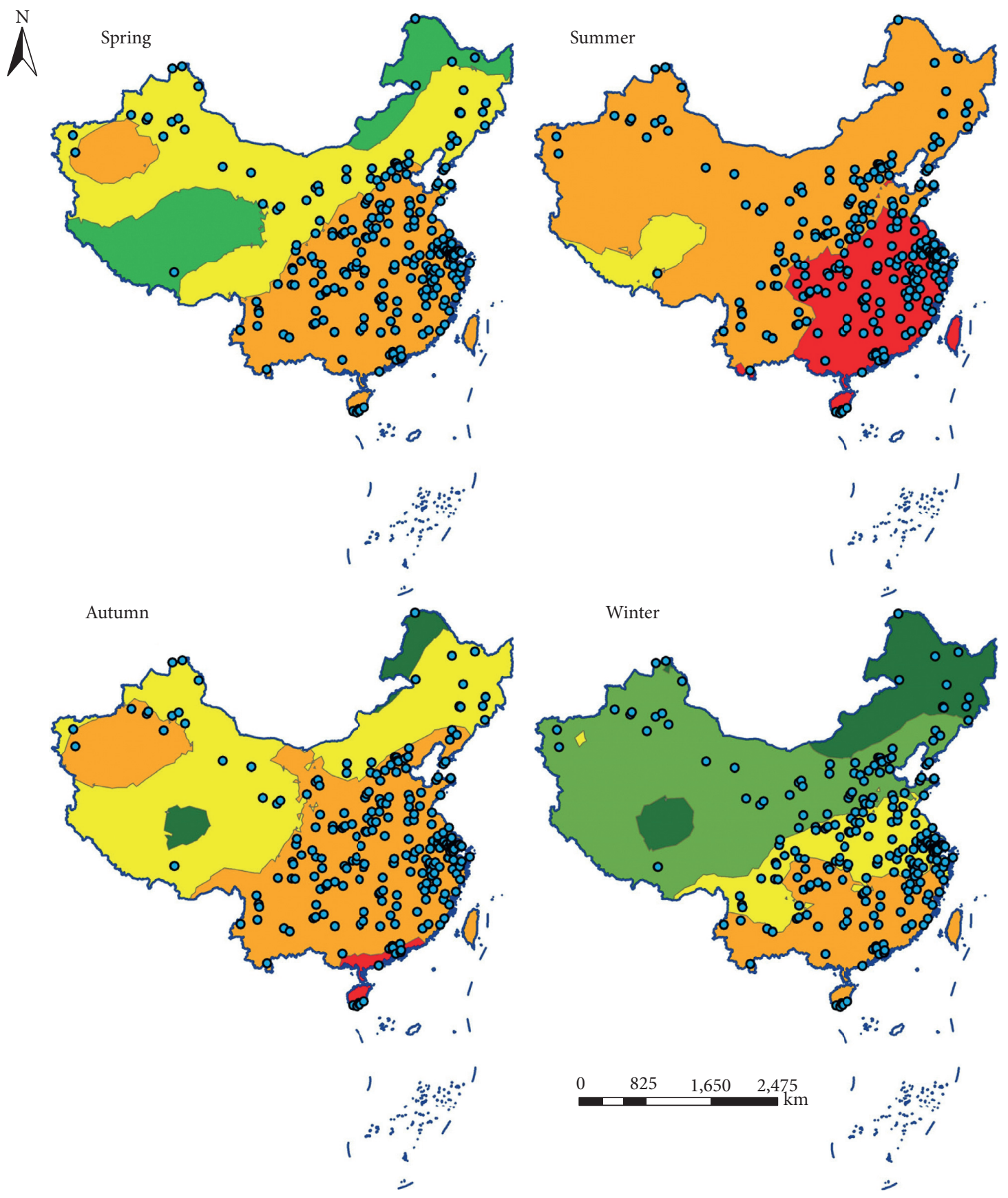

- National 5A tourist attraction

— National boundary

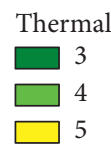

FIgURE 3: Spatial distribution of climate comfort levels of national 5A tourist attractions with respect to seasons.

high temperature and humidity is observed throughout the year because of the low latitudes of the tropical region. The best climate comfort level of 6 occurs only in January and December.

\section{Discussion}

This study is based on daily climate data of meteorological stations in the mainland of China. The density of 


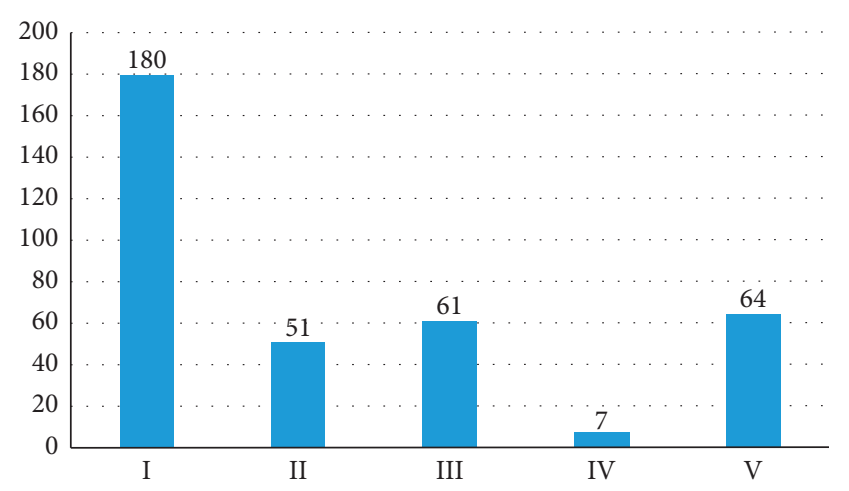

FIGURE 4: The number of national 5A tourist attractions with different comfort categories. I: "comfortable during spring and autumn"; II: "comfortable during spring, autumn, and winter"; III: "comfortable during spring, summer, and autumn"; IV: "uncomfortable during the four seasons"; and V: "comfortable during winter."

meteorological stations is gradually decreasing from the southeast coastal areas to the northwest inland areas due to the uneven geographical distribution of the site. For this reason, the accuracy of the climate comfort evaluation results is inevitably affected to some extent. Quite a fair number of national $5 \mathrm{~A}$ tourist attractions are located in the mountainous and water areas so the impact of altitude and water thermal inertia on climate comfort are represented. On the other hand, it is also necessary to integrate the Digital Elevation Model (DEM) data to improve the accuracy of the climate comfort evaluation [36]. Based on the seasonal and annual scale analysis, the impact of extreme and severe weather conditions are smoothed and concealed. In order to observe the actual fluctuations of climate comfort levels, the research should be carried out on smaller time scales [34]. Although the UTCI model is currently a state-of-the-art tool for climate comfort assessment, the standard scale can be adjusted considering the people's perception of the thermal environment, their physiological processes change, and adoption for the study area [36]. The assumption of standard personal characteristics such as age, gender, physical fitness, metabolic rate, and clothing behavior in this study is also another factor that brings some uncertainty to the results $[32,34,36]$. By taking the abovementioned factors into account, the results of this study would be more practical and accurate.

In addition, climate comfort is not fixed, and there are many influencing factors in the change of climate factors. Not all of the above research can be fully summarized $[35,37]$. The climate is affected by the change of solar radiation, the change of aerosol, and the change of atmospheric circulation, which leads to the constant change of climate. As an important part of the earthatmosphere system, aerosols affect the global radiation energy balance and water cycle such as rainfall and snowfall by combining greenhouse gas changes through direct radiation forcing, cloud albedo effect, and thermodynamic effect, thus causing regional and even global climate change [38-41]. Aerosol cooling of the surface and reduction of local water evaporation and water vapor content in the atmosphere by reducing thermal differences between land and sea and increasing atmospheric stability and decreasing incident solar radiation have resulted in a weakening of monsoon circulation and a decrease in monsoon precipitation $[42,43]$. Atmospheric aerosol particles and precipitation are more complex: on the one hand, the increase of aerosol concentration in dry areas or seasons may lead to the decrease of cloud droplet effective radius, which may delay or even inhibit precipitation $[44,45]$. On the other hand, precipitation is the main way of wet removal of aerosol particles [46, 47]. These will affect the climate comfort between regions [44-51]. In the future, the study of climate comfort should consider the influence of these factors and improve the study of climate comfort.

The findings in this study are expected to help to optimize the tourism industry and facilitate the development of national 5A tourist attractions in the mainland of China. There are fewer attractions in the northern and southwest of China although these regions have the best climate comfort level during summer. Thus, more high-quality resorts in these regions should be developed to attract tourists. In the southern parts of Hainan Island, for instance, winter resorts should be promoted to attract tourists who pursue comfortable climate conditions during winter.

\section{Conclusions}

This research aims to carry out climate comfort evaluation of national $5 \mathrm{~A}$ tourist attractions in the mainland of China. Our results show that the annual average climate comfort level in the study area is generally distributed in a strip-like spatial pattern along the latitudinal direction while the climate comfort level gradually decreases from south to north. And there are significant regional differences in terms of climate comfort between the southeast coastal areas and the northwest inland.

A similar spatial distribution of climate comfort is obtained for spring and autumn. The overall number of national 5A tourist attractions located in the comfortable climate zone with the climate comfort level of 6 is higher in spring and autumn while it is less in summer and winter. To extend the study, seasonal climate comfort levels are classified into five categories of "comfortable during spring and autumn," "comfortable during winter," "comfortable during spring, autumn, and winter," "comfortable during spring, summer, and autumn," and "uncomfortable during the four seasons." The best climate comfort level is obtained to be during "spring and autumn" where the associated attractions are located between the southeast of the line formed by Taihang, Qinling, and Wushan Mountains as well as north of Hainan Island with an elevation below 1000 meters. The attractions with the best climate comfort level during "spring, autumn, and winter" and those during "winter" occurred in the lower-latitude areas of the south of the middle and lower reaches of the Yangtze River. The attractions with the best climate comfort level during "spring, 
summer, and autumn" are distributed in the central part of China, near the Taihang and Qinling Mountains. Only 7 attractions in the south of Hainan Island are labeled as "uncomfortable during the four seasons." The best climate comfort level of 6 occurred only in January and December. The results of this study are expected to be helpful for the optimization of the tourism industry and the development of a high-quality tourism destination.

\section{Data Availability}

The meteorological data can be obtained from the China Meteorological Data Network.

\section{Conflicts of Interest}

The authors declare that there are no conflicts of interest regarding the publication of this paper.

\section{Acknowledgments}

This work was supported by the Natural Science Foundation of China (no. 41701323), Hubei Province Natural Science Foundation of China (no. 2019CFB766), and Fundamental Research Funds for the Central Universities (no. CCNU19TS005).

\section{References}

[1] K. Parsons, Human Thermal Environments: The Effects of Hot, Moderate and Cold Environments on Human Health, Comfort and Performance, Vol. 149, Taylor \& Francis, Milton, UK, 2014.

[2] L. Hill, O. W. Griffith, and M. Flack, "The measurement of the rate of heat loss at body temperature by convection, radiation and evaporation," Philosophical Transaction of Royal Society, vol. 207, pp. 183-220, 1916.

[3] K. Blazejczyk, Y. Epstein, G. Jendritzky, H. Staiger, and B. Tinz, "Comparison of UTCI to selected thermal indices," International Journal of Biometeorology, vol. 56, no. 3, pp. 515-535, 2012.

[4] Q. Q. Kong, J. Y. Zheng, and X. G. Wang, "Spatial pattern and temporal variation in thermal comfort in China from 1979 to 2014," Resources Science, vol. 38, pp. 1129-1139, 2016, in Chinese.

[5] A. Bigano, J. M. Hamilton, and R. S. J. Tol, "The impact of climate on holiday destination choice," Climatic Change, vol. 76, no. 3-4, pp. 389-406, 2006.

[6] D. Maddison, "In search of warmer climates? The impact of climate change on flows of British tourists," Climatic Change, vol. 49, no. 1, pp. 193-208, 2001.

[7] J. Nalau, S. Becken, S. Noakes, and B. Mackey, "Mapping tourism stakeholders' weather and climate informationseeking behavior in Fiji," Weather, Climate, and Society, vol. 9, no. 3, pp. 377-391, 2017.

[8] Y. X. Zeng, L. S. Zhong, H. C. Liu, and H. Yu, "Implications of overseas quantitative studies of climate change impact on tourism for domestic research," Journal of Natural Resources, vol. 34, pp. 205-220, 2019, in Chinese.

[9] F. C. Houghten and C. P. Yagloglou, "Determining lines of equal comfort," ASHVE Transactions, vol. 29, pp. 163-176, 1923.
[10] P. W. Li and S. T. Chan, "Application of a weather stress index for alerting the public to stressful weather in Hong Kong," Meteorological Applications, vol. 7, no. 4, pp. 369-375, 2000.

[11] C. P. Yaglou and D. Minard, "Control of heat casualties at military training centers," AMA Archives of Industrial Health, vol. 16, no. 4, pp. 302-316, 1957.

[12] E. C. Thom, "A new concept of cooling degree days," Air Condition Heat Ventil, vol. 54, pp. 73-80, 1957.

[13] P. Siple and C. F. Passel, "Measurements of dry atmospheric cooling in subfreezing temperatures," Proceedings of the American Philosophical Society, vol. 89, pp. 177-199, 1945.

[14] OFCM, Report on Wind Chill Temperature and Extreme Heat Indices: Evaluation and Improvement Projects, US Department of Commerce /National Oceanic and Atmospheric Administration, Office of the Federal Coordinator for Meteorological Services and Supporting Research, Washington, DC, USA, 2003.

[15] G. Jendritzky, R. de Dear, and G. Havenith, "UTCI-why another thermal index," International Journal of Biometeorology, vol. 56, no. 3, pp. 421-428, 2012.

[16] K. C. Parsons, Human Thermal Environments: The Effects of Hot, Moderate, and Cold Environments on Human Health, Comfort and Performance, Taylor \& Francis, Milton, UK, 2003.

[17] P. O. Fanger, Thermal Comfort: Analysis and Applications in Environmental Engineering, Copenhagen: Danish Technical, Lyngby, Denmark, 1970.

[18] R. R. Gonzalez, Y. Nishi, and A. P. Gagge, "Experimental evaluation of standard effective temperature a new biometeorological index of man's thermal discomfort: a new biometeorological index of man's thermal discomfort," International Journal of Biometeorology, vol. 18, no. 1, pp. 115, 1974.

[19] H. Mayer and P. R. Höppe, "Thermal comfort of man in different urban environments," Theoretical and Applied Climatology, vol. 38, no. 1, pp. 43-49, 1987.

[20] J.-C. Xi, Q.-Q. Kong, and X.-G. Wang, "Spatial polarization of villages in tourist destinations: a case study from Yesanpo, China," Journal of Mountain Science, vol. 12, no. 4, pp. 1038-1050, 2015.

[21] Y. Ding, S. Wang, J. Zheng, H. Wang, and X. Yang, Climate in China, Science Press, Beijing, China, 2013, in Chinese.

[22] Q. Ge, Q. Kong, J. Xi, and J. Zheng, "Application of UTCI in China from tourism perspective," Theoretical and Applied Climatology, vol. 128, no. 3-4, pp. 551-561, 2017.

[23] J. C. Lam, K. K. W. Wan, S. L. Wong, and T. N. T. Lam, "Longterm trends of heat stress and energy use implications in subtropical climates," Applied Energy, vol. 87, no. 2, pp. 608-612, 2010.

[24] L. J. Ma, G. N. Sun, and J. J. Wang, "Evaluation of tourism climate comfortableness of coastal cities in the eastern China," Progress in Geography, vol. 28, pp. 713-722, 2009, in Chinese.

[25] D. Y. Feng, X. F. Qiu, and J. M. Huang, "The distribution of the apparent temperatures in summer in China," Meteorological Monthly, vol. 15, pp. 21-26, 1990, in Chinese.

[26] S. Wang, H. Tian, W. S. Xie, W. A. Tang, and X. Ding, "A study on variations and comprehensive zoning of climate comfort degree in Anhui province in the Past 50 years," Progress in Geography, vol. 31, no. 1, pp. 40-45, 2012, in Chinese.

[27] Y. Z. Fan and L. X. Guo, "The climate suitability of tourism at the coastline destinations of China," Journal of Natural Resources, vol. 13, pp. 304-311, 1998, in Chinese.

[28] B. X. Zhao, L. Wang, and D. Y. Cheng, "Comparison of spatial interpolation method for meteorological data and distribution 
characteristic in Anhui province," Research of Soil and Water Conservation, vol. 24, pp. 141-145, 2017, in Chinese.

[29] P. Bröde, D. Fiala, K. Błażejczyk et al., "Deriving the operational procedure for the universal thermal climate index (UTCI)," International Journal of Biometeorology, vol. 56, no. 3, pp. 481-494, 2012.

[30] P. Qiao, P. Li, Y. Cheng et al., "Comparison of common spatial interpolation methods for analyzing pollutant spatial distributions at contaminated sites," Environmental Geochemistry and Health, vol. 41, no. 6, pp. 2709-2730, 2019.

[31] A. Matzarakis, M. Hämmerle, E. Koch, and E. Rudel, "The climate tourism potential of alpine destinations using the example of Sonnblick, Rauris and Salzburg," Theoretical and Applied Climatology, vol. 110, no. 4, p. 645, 2012.

[32] T.-P. Lin and A. Matzarakis, "Tourism climate information based on human thermal perception in Taiwan and eastern China," Tourism Management, vol. 32, no. 3, pp. 492-500, 2011.

[33] C. Koppe and G. Jendritzky, "Inclusion of short-term adaptation to thermal stresses in a heat load warning procedure," Meteorologische Zeitschrift, vol. 14, no. 2, pp. 271-278, 2005.

[34] Z. Li, W. K. M. Lau, V. Ramanathan et al., "Aerosol and monsoon climate interactions over Asia," Reviews of Geophysics, vol. 54, no. 4, p. 866, 2016.

[35] T. P. Ramanathan and O. B. Toon, "Absorption of visible radiation in atmosphere containing mixtures of absorbing and nonabsorbing particles," Applied Optics, vol. 20, no. 20, pp. 3661-3667, 1981.

[36] X. Y. Zhang, C. Jiang, J. X. Sun, and M. F. Zhou, "Spatiotemporal variations and influencing factors of thermal comfort at different elevations," Chinese Journal of Applied Ecology, vol. 29, pp. 2808-2818, 2018, in Chinese.

[37] R. J. Charlson, S. E. Schwartz, J. M. Hales et al., "Climate forcing by anthropogenic aerosols," Science, vol. 255, no. 5043, pp. 423-430, 1992.

[38] X. Xia, H. Chen, P. Wang et al., "Variation of column-integrated aerosol properties in a Chinese urban region," Journal of Geophysical Research Atmospheres, vol. 111, 2006.

[39] X. X. Gao, H. L. Gui, Y. Chen et al., "Spatiotemporal characteristics of aerosols and its effects on cloud and precipitation during summer over typical regions in China," Journal of Meteorology and Environment, vol. 36, no. 1, pp. 11-20, 2020.

[40] H. Zhang, Z. Wang, P. Guo, and Z. Wang, "A modeling study of the effects of direct radiative forcing due to carbonaceous aerosol on the climate in east Asia," Advances in Atmospheric Sciences, vol. 26, no. 1, pp. 57-66, 2009.

[41] N. Paldor, "On the estimation of trends in annual rainfall using paired gauge observations," Journal of Applied Meteorology and Climatology, vol. 47, no. 6, pp. 1814-1818, 2008.

[42] S. Fengfei, Z. Tianjun, and Q. Yun, "Responses of east Asian summer monsoon to natural and anthropogenic forcings in the 17 latest CMIP5 models," Geophysical Research Letters, vol. 2, 2014.

[43] U. Schneider, A. Becker, P. Finger, A. Meyer-Christoffer, M. Ziese, and B. Rudolf, "GPCC's new land surface precipitation climatology based on quality-controlled in situ data and its role in quantifying the global water cycle," Theoretical and Applied Climatology, vol. 115, no. 1-2, 2014.

[44] Z. Zheng, C. Zhao, S. Lolli et al., "Diurnal variation of summer precipitation modulated by air pollution: observational evidences in the Beijing metropolitan area," Environmental Research Letters, vol. 15, no. 9, 2020.
[45] J. Guo, M. Deng, S. S. Lee et al., "Delaying precipitation and lightning by air pollution over the Pearl river delta. Part I: observational analyses," Journal of Geophysical Research: Atmospheres, vol. 121, no. 11, pp. 6472-6488, 2016.

[46] M. Mircea, S. Stefan, and S. Fuzzi, "Precipitation scavenging coefficient: influence of measured aerosol and raindrop size distributions," Atmospheric Environment, vol. 34, no. 29-30, pp. 5169-5174, 2000.

[47] H. Zhao and C. Zheng, "Monte Carlo solution of wet removal of aerosols by precipitation," Atmospheric Environment, vol. 40, no. 8, pp. 1510-1525, 2006.

[48] Z. Wang, L. Lin, M. Yang, Y. Xu, and J. Li, "Disentangling fast and slow responses of the east Asian summer monsoon to reflecting and absorbing aerosol forcings," Atmospheric Chemistry and Physics, vol. 17, no. 18, pp. 11075-11088, 2017.

[49] N. K. Shahi, S. Rai, and A. K. Sahai, "The relationship between the daily dominant monsoon modes of South Asia and SST," Theoretical and Applied Climatology, 2020.

[50] D. M. Westervelt, Y. You, X. Li, M. Ting, D. E. Lee, and Y. Ming, "Relative importance of greenhouse gases, sulfate, organic carbon, and black carbon aerosol for south Asian monsoon rainfall changes," Geophysical Research Letters, vol. 47, no. 13, pp. 1-10, 2020.

[51] Y. Qian and F. Giorgi, "Regional climatic effects of anthropogenic aerosols? The case of southwestern China," Geophysical Research Letters, vol. 27, no. 21, pp. 3521-3524, 2000. 